\title{
PIBID LETRAS-UMA REFLEXÃO SOBRE A PRÁTICA DOCENTE DOS SUPERVISORES
}

\author{
Bruna Vasconcelos Santana ${ }^{1}$ \\ Maria Fernanda Brito Chaves ${ }^{2}$ \\ Marilene Sacramento Miranda ${ }^{3}$
}

\begin{abstract}
Resumo: Este trabalho relata as experiências de formação e as práticas pedagógicas das professoras supervisoras do subprojeto PIBID Letras no ano de 2016. No qual o objetivo foi analisar a articulação entre teoria e prática docente e os mecanismos pedagógicos pertinentes ao trabalho do bolsista discente no contexto da escola pública. Para tanto a discussão desse processo será sustentada nos Novos Estudos do Letramento, visto que estes definem letramento como sendo um conjunto de práticas de usos sociais da leitura e da escrita.
\end{abstract}

Palavras-chave: Letramento; Experiência; Mediação; Interação; Formação.

Introdução

Este relato consiste na exposição de um conjunto de atividades desenvolvidas pelo subprojeto PIBID Letras, identificado aos estudos do letramento e da formação das professoras supervisoras. As ações do subprojeto foram organizadas em um esforço de reflexão conceitual e renovação pedagógica que possibilitasse uma aproximação da complexidade do processo educacional contemporâneo. Nesse esforço estão envolvidos os docentes em formação e os sujeitos que formam o contexto escolar da Educação Básica - docentes supervisores, gestores, comunidade participante e os alunos, protagonistas do processo e alvo principal da ação formativa na licenciatura. Nesse contexto, cabe ao supervisor incentivar o bolsista a examinar sua própria prática, isto é, o formando deve aprender a delimitar adversidades, conjecturar, registrar as informações e examiná-las. E nesta reflexão, a partir do que se sabe, analisar o todo por diferentes áreas de conhecimento, assim como da experiência adquirida em seu percurso como aluno e professor.

Para tanto, o subprojeto PIBID Letras intencionou, desde seu início, instituir um espaço de reflexão teórico-metodológica e de ações didáticas de caráter colaborativo com a licenciatura, focando, principalmente, nos saberes desenvolvidos durante as práticas relacionadas à leitura e escrita.

Em relação as atividades do subprojeto foram distribuídas em três escolas da rede estadual baiana: o CPM-Colégio da Polícia Militar Francisco Pedro de Oliveira, localizado na Cidade de Candeias, região metropolitana de Salvador, que funciona nos dois turnos, sendo que as ações do PIBID ocorrem no turno vespertino no Ensino Fundamental II; a Escola de Primeiro Grau Jesus Cristo 
situada no bairro periférico de Pau da Lima em Salvador-Ba e o Colégio Estadual Raphael Serravalle, situado no bairro da Pituba em Salvador-Ba, que funciona nos três turnos e atende a aproximadamente dois mil alunos, contudo a atuação do PIBID é realizada no vespertino, em turmas da terceiro ano do Ensino Médio.

Por fim, o subprojeto PIBID Letras propôs, desde o início de sua atuação, o desafio de aproximar os graduandos das escolas públicas, contando com o acompanhamento das supervisoras no direcionamento dos bolsistas discentes em relação à realidade escolar. Este relato tem como finalidade última apresentar as experiências que foram amealhadas ao longo desse período. Em razão disso, propõe-se conduzir uma breve reflexão teórica, seguida pela exposição sucinta dos trabalhos desenvolvidos nas escolas, considerando principalmente o desafio do ensino da Língua Portuguesa e do letramento. O relato agora apresentado faz referência às ações do projeto no período letivo de 2016.

\section{Pressupostos teóricos}

Os primeiros passos do projeto na direção de seus objetivos foram aproximar o licenciando da realidade escolar e propor-Ihes um objetivo comum: refletir sobre e elaborar atividades sequenciadas que possam ser aplicadas em sala de aula afim de conduzir um aprendizado reflexivo e consciente no sujeito aprendente. Nesse momento inicial, as ações foram fundamentadas no entendimento de que as capacidades de linguagem relativas à leitura e à escrita são o fundamento da experiência escolar. Conforme recorda Antunes (2003, p.67), "a atividade da leitura completa a atividade da produção escrita".

Outrossim, Vasconcellos $(2005$, p. 56) ratifica que o processo da construção da aprendizagem acontece a partir das especificidades que a compõem, utilizando-se de uma metodologia dialética expressa através de três fundamentos: a mobilização dos conhecimentos prévios, a construção do conhecimento e a elaboração e expressão da síntese do conhecimento.

Nesse sentido, Freire (1996, p. 153) esclarece que é possível potencializar todos os agentes educativos enquanto instituições formadoras. Diante disso, a escola poderá tornar-se politizada positivamente pela liberdade e consciência presentes em todos os espaços sociais e pelo movimento transformador da vida cotidiana.

Freire corrobora ainda afirmando que o círculo de cultura, a rigor, não se ensina, mas sim se aprende em reciprocidade de consciências. No entanto, o que com frequência impera, no contexto da escola, é a versão contrária: o não acreditar no outro faz toda a diferença, trazendo a impossibilidade de uma educação à base do diálogo, pois ser o construtor desta história é tornar-se responsável para o mundo. 
No entanto, não se deve esquecer de que desconstruir o paradigma de uma educação opressora é difícil, mas não é impossível. Precisamos pensar em mobilizar todo o contexto em açãoreflexão-ação, pois conscientizar - dialogar - refletir é o caminho para a liberdade. Ninguém educa ninguém, ninguém educa a si mesmo, os homens se educam entre si, mediatizados pelo mundo. (FREIRE, 1996, p. 95).

\section{Metodologia}

As atividades do subprojeto Letras, coordenadas pelas Prof. a Daniele de Oliveira e Simone Bueno Borges da Silva (Instituto de Letras- UFBA), iniciaram-se em março de 2016, com encontros de formação com bolsistas e supervisores, divisão dos grupos de trabalho pelas escolas, visitas dos bolsistas às escolas envolvidas, acompanhamento das aulas das professoras supervisoras, planejamento e execução de oficinas.

Paralelamente, as etapas no processo de formação de supervisores e bolsistas aconteciam nos encontros quinzenais para estudo das teorias que norteariam o nosso trabalho. Nesses encontros estudamos: Pedagogia do oprimido de Freire (2005); Pedagogia dos multiletramentos de Rojo(2013); Gêneros textuais no ensino da língua de Marcuschi(2008).

Dessa forma, os momentos de estudo nos fizeram refletir sobre o papel do professor a partir da ideia de que se faz necessário considerar o meio cultural do aprendiz, dar as informações solicitadas por eles e criar condições favoráveis à dinâmica do grupo. Além disso, nos levou a discutir e refletir sobre a responsabilidade do educador ao organizar um currículo, planejar atividades e criar condições para que os sujeitos que constituem as salas de aula sejam capazes de agir e refletir sobre o mundo para transformá-lo (FREIRE, 2005).

\section{Hora da prática}

\section{Escola de primeiro Grau Jesus Cristo - Pau da Lima}

Este presente texto traz um relato da prática pedagógica realizada com estudantes da rede estadual de ensino na Escola de 1o grau Jesus Cristo, localizada na periferia de Pau da Lima em Salvador-Ba, dentro do Centro Espírita Mansão do caminho, no primeiro semestre de 2016. O trabalho teve como eixo temático a Cidadania e o gênero textual adotado foi memorialístico, sendo orientado pela ótica dos estudiosos das Olimpíadas de Língua Portuguesa e considerando questões de natureza sociocultural do uso da língua portuguesa e das condições de produção.

Esta experiência teve como objetivo ampliar a capacidade leitora e escritora dos aprendizes envolvidos e como objetivos específicos, foi previsto, pelo grupo, identificar os elementos 
constitutivos da organização interna do gênero memorialístico, fazê-los apropriar-se da capacidade de construir uma analise contextual do tempo e ampliar as possibilidades de expressão e de autoreconhecimento nas diversas vozes que circulam a partir das informações contidas nos textos.

Em vista disso, a primeira etapa desta atividade foi possibilitar um vínculo inicial entre a escrita dos alunos e suas memórias, despertando assim o desafio de torná-los escritores da sua própria história, a partir de representações mentais com as quais poderiam estabelecer um processo de resgate de situações. A priori, foram conduzidas atividades de leitura e debate o texto de Divulgação Científica Memória de Marinho Lopes; o poema memorialístico Profundamente de Manuel Bandeira; o artigo de opinião Exercício de otimismo de Lya Luft, culminando na elaboração de uma pesquisa sobre a família.

Durante este processo de mobilização de conhecimentos, a efetiva ação que sensibilizou os discentes foi a roda de conversa realizada com a presença da diretora da escola, a professora Rosangela Cardoso; a professora de História Dilza Xavier e a Servidora D Antonia Brito.
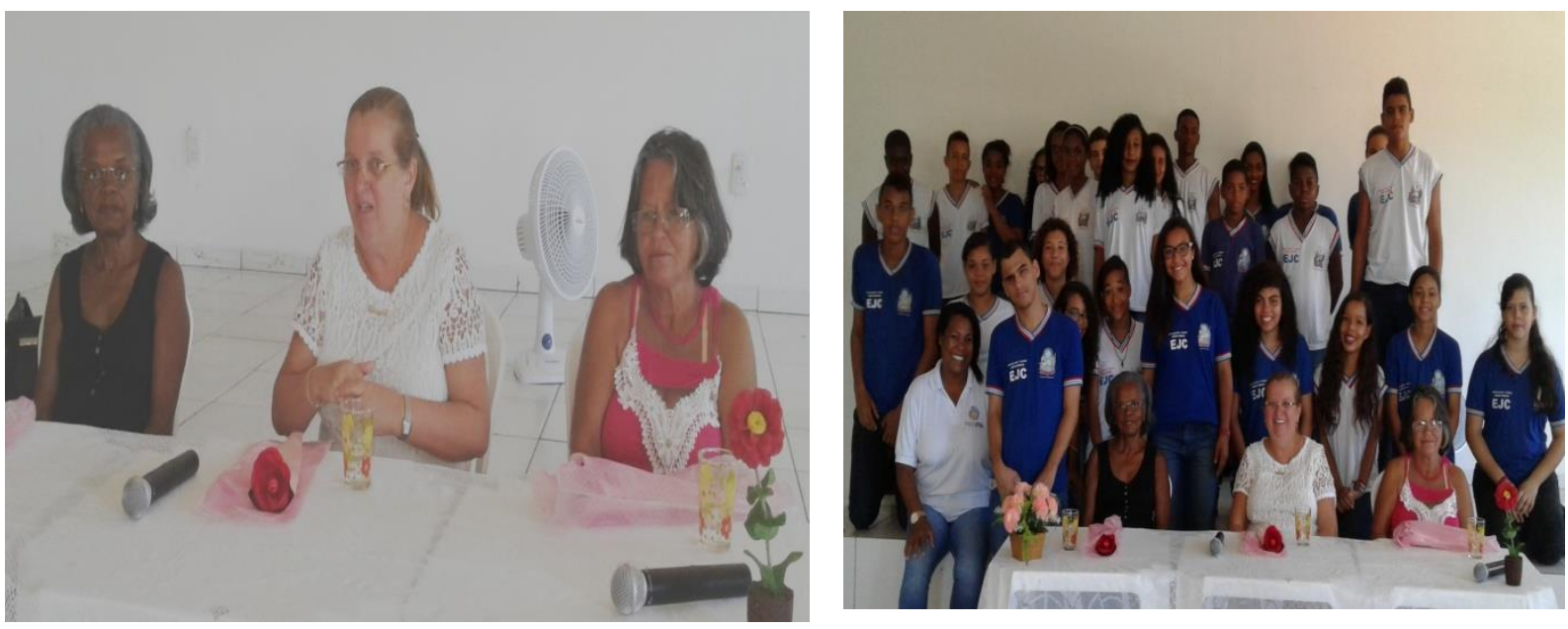

A figura acima representa o momento de socialização da turma com as convidadas para roda de conversa. Após, a diretora e os demais servidores que falaram das memórias e o que contribuiu para o caminho de suas vidas, os discentes se sentiram à vontade para escrever o gênero textual sugerido.

Por conseguinte, a ação do projeto desenvolvido possibilitou o confronto entre o sujeito (os alunos) e sua relações internas e externas, estabelecendo assim uma elaboração efetiva do conhecimento, a partir de construções produtivas, tais como um texto memorial em forma de poema, cujo título referencia o passado; o uso de estrofes e versos com rimas e frases com efeito de sentido para referendar a memória; e, ainda, um movimento de escrita constituído de idas e vindas; assim como um texto com narrativa poética baseado em fatos reais, escolhido por discutir e ilustrar 
uma lembrança situacional, trazendo neste contexto o uso de elementos de coerência e coesão textual.

Para referenciar teoricamente os nossos estudos e as atividades realizadas em sala de aula utilizamos como parâmetro os estudos de Kleiman (2013), que concebe leitura como prática social; Freire (2011), que reconhece a historicidade no conhecimento de mundo do educando; Marcuschi (2008), que considera o gênero textual como um campo aberto pelo seu dinamismo autônomo e, ainda, pelo papel social que desempenha; Vasconcellos (2005), que acredita que a sala de aula é o centro dos acontecimentos para o conhecimento mediados pela realidade de cada um dos sujeitos.

Em se tratando de metodologia utilizamos, para este estudo, a etnografia escolar, visto que assim como André (2005), que compreende o estudo da prática escolar como um processo de reconstrução, desvelando dimensões das práxis escolares. No que tange em relação à escolha pelo texto memorialístico, foi por compreendermos que esta é uma escrita reveladora de sentimentos e de argumentos numa relação dialógica da leitura dos textos estudados com a vivência dos aprendizes.

Como resultado desta prática pedagógica foi possível verificar que os estudantes ampliaram a capacidade leitora e escritora em muitos aspectos. Percebemos também que $65 \%$, deles, conseguiram estabelecer a relação entre a proposta e o que se pretendia nela. Que $82 \%$ perceberam informações implícitas no contexto e foram capazes utilizar esta informação para uso da escrita. $E$ que $50 \%$ reconheceu o efeito de sentido decorrente da exploração de recursos ortográficos e/ou morfossintáticos e os argumentos oferecidos para sustentá-la.

\section{Colégio Estadual Raphael Serravalle - Pituba}

As atividades do subprojeto Pibid Letras foram iniciadas no Colégio Estadual Raphael Serravalle, localizado no bairro da Pituba, em Salvador-Ba,no segundo semestre do ano letivo 2016. Fazem parte da equipe a professora supervisora e seis bolsistas discentes, graduandos do curso de Letras da Universidade Federal da Bahia - UFBA.

A supervisora participou, com os bolsistas, de seminários e encontros de formação. Esses momentos foram significativos, posto que proporcionassem socializações de dúvidas, reflexões e experiências. São promovidos, na Unidade Escolar de atuação, encontros para avaliação, análise e ponderação sobre o trabalho desenvolvido, as dificuldades de aprendizagem dos alunos, além do planejamento de ações para o aprimoramento dos processos de ensino-aprendizagem e dos projetos que estiverem em andamento. Os encontros com os bolsistas fortalecem a equipe, "dando maior coesão e interação, e não apenas [como] o ajuntamento de profissionais que, por mais brilhantes 
que sejam se não desenvolvem esta competência de trabalhar coletivamente, não garantem o processo emancipatório" (VASCONCELLOS 2002, P.120).

Após o acompanhamento de aulas ministradas pela professora supervisora e o planejamento de ações, os bolsistas iniciaram as atividades com os alunos, uma vez que se concebe a escola como um lugar de formação e produção de conhecimentos e saberes, onde se promove um diálogo entre a prática e a teoria. Nestes momentos, a supervisora acompanhou, participou, incentivou, articulou, mediou e colaborou com a construção de identidades e práticas, permitindo que cada bolsista dê sentido à sua experiência e busque a evolução do seu desempenho.

Em novembro de 2016 foi realizada, pelos bolsistas, uma oficina cujo tema central foi o Modernismo no Brasil. A atividade foi desenvolvida em turmas do terceiro ano do Ensino Médio, com alunos de classe média e média baixa, faixa etária entre 16 e 23 anos. Objetivando-se a compreensão da importância histórica do Brasil para o desenvolvimento dos movimentos literários da época; o estudo e a análise da poesia Modernista; a distinção das obras modernistas das demais produções do século; a percepção da riqueza das temáticas utilizadas pelos autores do Modernismo Brasileiro; o reconhecimento da importância da construção crítica, o valor da literatura e das demais artes para a compreensão de si mesmo e do mundo, durante os movimentos literários da época; o conhecimento do contexto sociocultural das fases do Modernismo; a identificação das características da produção literária modernista e o diálogo intertextual que as produções contemporâneas estabelecem com alguns de seus exemplares; a interação com textos literários, procurando compreender as possíveis relações que, estas, mantém com os fatores econômicos, sociais e culturais da época; o desenvolvimento, pelo contato com a literatura, da sensibilidade para o estético e para as relações humanas.

Foi feito um breve levantamento dos conhecimentos prévios a respeito do assunto - 0 entendimento sobre o Modernismo e como o definia. A partir disto, construíram alguns conceitos, que foram analisados e comparados aos encontrados em dicionários, livros e páginas da internet. Tendo a noção definida, iniciou-se o estudo de obras modernistas, com a exposição de vídeos, poesias, trechos de textos em prosa e músicas, e a sua importância para a construção histórico social do Brasil. Feito isso, solicitou-se aos alunos que formassem grupos, a fim de que interpretassem letras de músicas e produções literárias referentes às fases abordadas. À partir das observações, estabeleceu-se a intertextualidade com a situação atual do país e com as obras contemporâneas escolhidas pelo grupo. Folhas de papel ofício foram distribuídas para que os alunos desenvolvessem produções críticas e culturais baseadas no Modernismo. E assim, foi montado um mural interativo para a socialização das produções, que posteriormente foram apresentadas no sarau literário, organizado pelos próprios alunos, com o auxílio de professores e dos bolsistas do PIBID Letras, o qual foi um sucesso absoluto, pela riqueza das obras apresentadas. 


\section{CPM - Colégio Militar Francisco Pedro de Oliveira}

Para desenvolver as atividades em sala de aula foram realizadas várias reuniões com as coordenadoras do Pibid e demais supervisoras e bolsistas discentes do grupo e também reuniões com o grupo.

Nessas reuniões, discutiu sobre o nível de aprendizagem dos estudantes, as dificuldades apresentadas por eles e o que faríamos para sanar tais dificuldades. Nesses encontros, após várias discussões sobre alguns temas resolvemos trabalhar com tema: Resgatando valores em sala de aula, pois percebemos que havia necessidade, devido à fala de alguns sobre preconceito e discriminação. Partindo dessa necessidade elaboramos o plano de ação e as sequências didáticas. Para tanto, cada bolsista ficou responsável para pesquisar sobre o tema e na próxima reunião ou via email ou WhatsApp apresentar para os colegas.

Na primeira atividade aplicada em sala de sala foi apresentado, aos alunos, o plano de trabalho e a forma de execução das atividades. Os alunos receberam bem a ideia e sugeriram escrever textos voltados para o tema. A segunda atividade os bolsistas levaram uns slides sobre o livro "Um Mundinho Para Todos" - Ingrid Biesemeyer Bellinghausen., que seria estudado. Eles apresentaram os slides e durante a exibição os próprios estudantes faziam interferências, dando opiniões sobre o tema a ser discutido, como por exemplo, discriminação é crime, não podemos ter preconceito, que devemos respeitar todos, independente da cor, religião ou classe social. Após esse momento foi entregue aos estudantes o livro e todos manusearam e descobriram que também era escrito em braile, ou seja, também para o para deficiente visual

Em seguida, eles falaram das cores o porquê, pois era para chamar atenção cada tonalidade e foram detalhes que nos surpreendeu. Alguns alunos pediram para ler, foi uma aula dinâmica, na qual todos participaram. Nas demais aulas continuaram as atividades e discussões sobre o tema.

Após a aplicação das atividades os alunos produziram histórias em quadrinhos, para tanto, eles foram orientados a planejar a escrita para depois fazer um primeiro texto, os alunos foram resistentes, pois, eles não gostam de fazer por achar que é perda de tempo, preferem escrever direto. Nesse momento foi discutido a importância de planejar, revisar, organizar e reescrever.

Durante o processo de produção dos textos e quando os alunos apresentavam dificuldades eram auxiliados por um dos bolsistas discentes ou pela supervisora. No decorrer das atividades foram feitas algumas leituras e nesse momento eles mesmos percebiam que faltava algo em seu texto. Os outros alunos ao ouvir a leitura dos colegas releram seus textos e sinalizavam que faltavam algumas palavras. Ao término da aula os textos foram recolhidos e os bolsistas terminaram a correção em casa, foi conversado com eles e orientado para não riscar e sim sinalizar e na próxima continuaríamos. 
Na seguinte retomamos as correções, os textos foram devolvidos aos alunos com algumas observações e foram levantados vários questionamentos sobre ortografia e coerência. Nesse cenário, os estudantes passaram a entender a importância de primeiro planejar a escrita.

Assim ao final dessa experiência os estudantes foram capazes de distinguir entre tema e assunto, reconhecer os elementos estruturais dos textos estudados em sala de aula, usar adequadamente os recursos linguísticos, desenvolveram a compreensão leitora, aprenderam a ler a palavra e a imagem e a escrever gênero textual solicitado. Percebeu-se que essas atividades foram bem aceitas pelos estudantes

\section{Considerações Finais}

Diante do que foi apresentado neste artigo, é notório o fato de que o subprojeto do PIBIDLetras tem contribuído para um novo olhar na escola pública, onde o ensino e a aprendizagem sejam possíveis, e a escola pública esteja cada vez mais alinhada com os princípios formativos, e torne-se de fato um espaço de produção (ou construção) de conhecimento e sua efetivação na vida dos envolvidos de forma consciente, significativa e benéfica. Os grupos de trabalho têm experimentado situações diversas, como a crescente aceitação e integração dos alunos, professores e gestores, que colaboram para a formação contínua dos bolsistas de graduação.

Durante a realização dos trabalhos, assumimos o desafio de relacionar o conteúdo científico com o senso comum, e isso sem dúvida facilitou o andamento das ações.

Por último destacamos a importância do acolhimento da gestão da escola com o PIBID, como também a participação dos professores das unidades escolares. Essa "parceria" engrandece ainda mais a essência do programa, e é fator primordial para o alcance dos objetivos.

\section{Referências}

ANTUNES, Irandé. Aula de Português: Encontro\& Interação. São Paulo: Parábola Editorial, 2003.

VASCONCELLOS, Celso dos santos, Construção do conhecimento em sala de aula, 18a Ed. São Paulo, Libertad, 2005.

Resgate do professor como sujeito de transformação. 13a Ed. São Paulo, Libertad, 2001

FREIRE, Paulo. Pedagogia da autonomia: saberes necessários à prática educativa. 43. ed, São Paulo: Paz e Terra, 2011.

Pedagogia do Oprimido, 17a. ed Rio de Janeiro, Paz e Terra,2005

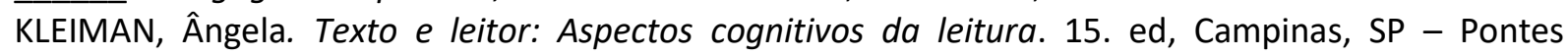
Editores, 2013. 
MARCUSCHI, Luiz Antonio. Produção textual, análise de gênero e compreensão. - São Paulo: Parábola Editorial, 2008.

ROJO, Roxane, Escola Conetada: os multiletramentos e as TICs. São Paulo. Parabola. 2013.

MARLI, Elisa D. A. Andre, Etnografia da prática escolar. São Paulo: Editora Papirus. 2005. 